\title{
Public attitude towards wastewater reuse for irrigated agriculture in Saudi Arabia
}

\author{
A. A. Alataway ${ }^{1}$, M. R. Ness ${ }^{2} \&$ J. W. Gowing ${ }^{1}$ \\ ${ }^{1}$ School of Agriculture, Food \& Rural Development, \\ Newcastle University, UK \\ ${ }^{2}$ Business School, Newcastle University, UK
}

\begin{abstract}
This study paper provides a general overview of the survey-based part of a study concerning wastewater reuse. This study was carried out in the Kingdom of Saudi Arabia (KSA), which is an arid region with limited freshwater resources. There is an urgent need to utilise non-conventional water resources (i.e. desalination and wastewater). A survey was conducted, and targeted a total of 400 eligible consumers to determine public attitude towards wastewater reuse practices in two main agricultural cities within the KSA. Namely Al-Hassa where there is an existing large-scale wastewater reuse project for unrestrictedirrigation, and Tabouk where there is a very limited wastewater ruse project; mainly irrigating beautification trees in small-scale. Particular emphasis is given to a scale of the acceptability of wastewater reuse. The content of the paper concerns the development of the scale, evaluation of the scale for validity and reliability and, identification of the dimensions of scale using factor analysis. Development of the scale resulted in twelve measures designed as five-point agreement scores $(1=$ strongly disagree, $5=$ strongly agree $)$. Scale reliability using Cronbach's alpha coefficient produced an alpha coefficient of 0.9, which indicates very high reliability. Factor analysis of the scale identified three dimensions of the acceptability of wastewater reuse. In descending order of importance these were defined respectively as the acceptability of agricultural use, domestic use and public use.
\end{abstract}

Keywords: wastewater reuse, irrigation, public attitude, acceptance. 


\section{Introduction}

Water scarcity, defined in terms of access to water, is a critical constraint to agriculture in many areas of the world. A fifth of the world's population (more than 1.2 billion people) live in areas of physical water scarcity, lacking enough water for everyone's demands Comprehensive Assessment of Water Management in Agriculture [1]. In less than 15 years from now, 3 billion citizens who will live in 48 countries that will be affected by water scarcity. One of those countries is Kingdom of Saudi Arabia (KSA), where the annual water resource availability per capita is already less than $1000 \mathrm{~m}^{3}$ (Hinrichsen et al. [2]). This information presents no surprise as most of the KSA is an arid region with limited freshwater resources. The annual rainfall is less than $200 \mathrm{~mm}$ in most parts of the country (Abderrahman [3]). The national water balance indicates that there is more than 14 billion $\mathrm{m}^{3}$ net deficit in water resources (Table 1), which is met by extracting water from non-renewable deep aquifers.

Table 1: $\quad$ The KSA national water balance in $2010\left(\right.$ Million $\mathrm{m}^{3}$ ).

\begin{tabular}{|cc|}
\hline Water demand & 18,300 \\
\hline Natural renewable resources available $^{1}$ & 1,800 \\
\hline Other renewable resources available $^{2}$ & 2,200 \\
\hline Total available & 4,000 \\
\hline Net deficit $^{3}$ & 14,300 \\
\hline
\end{tabular}

${ }^{1}$ Includes surface water and renewable groundwater

${ }^{2}$ Includes desalination and reclamation of wastewater

${ }^{3}$ Use of non-renewable groundwater resources

Adapted: Al-Ibrahim [4].

In view of the growing problem of water scarcity there is an urgent need to utilise non-conventional water resources (i.e. desalination and wastewater). Given the dominance of the agriculture sector which is the largest water consumer, except in Europe and Northern America (FAO [5]), wastewater reuse in agriculture is becoming an increasingly important consideration (Scott et al. [6]).

However, considering frequent failures of wastewater treatment facilities over the world, there are some factors such as beliefs, fear, perception, lack of knowledge and lack of trust, which create public antipathy towards recycling projects (Wegner-Gwidt [7]; Jeffrey and Temple [8]). It is therefore apparent that "future success of wastewater treatment projects will depend on understanding how people make risk judgements" (Torres [9]). It is important to acknowledge that "Many communities support the concept of water re-use, but many technically sound schemes have failed because communities have rejected them" (Po et al. [10]).This also, shows that when the reuse of wastewater comes closer to human contact; communities' acceptance of using such water is reduced. The conceptualisation of "yuck" factor plays an important role in people's attitude towards wastewater reuse. 
Research carried out on public attitude towards water reuse in Doha; Qatar (Ahmad [11]) showed that community was likely to be against wastewater reuse. The study emphasised that there is a need for better channel of communication between public and water department toward water conservation, treated water quality and reuse. In this study the majority of respondents were against the options of reuse of wastewater in gardens, car washing, toilet flushing, farming and industries. In that time the study recommended a restricted use of wastewater such as watering landscape planting and agriculture productions that are used as forage to feed livestock.

A survey carried out in Middle East determined urban citizens' attitude toward reuse options of treated wastewater. Only $13 \%$ of the participants supported the option of wastewater reuse in irrigated fruit and vegetable productions. However, this study mentions that up to date there has not been any research to investigate large-scale urban reuse projects (Friedler et al. [12]).

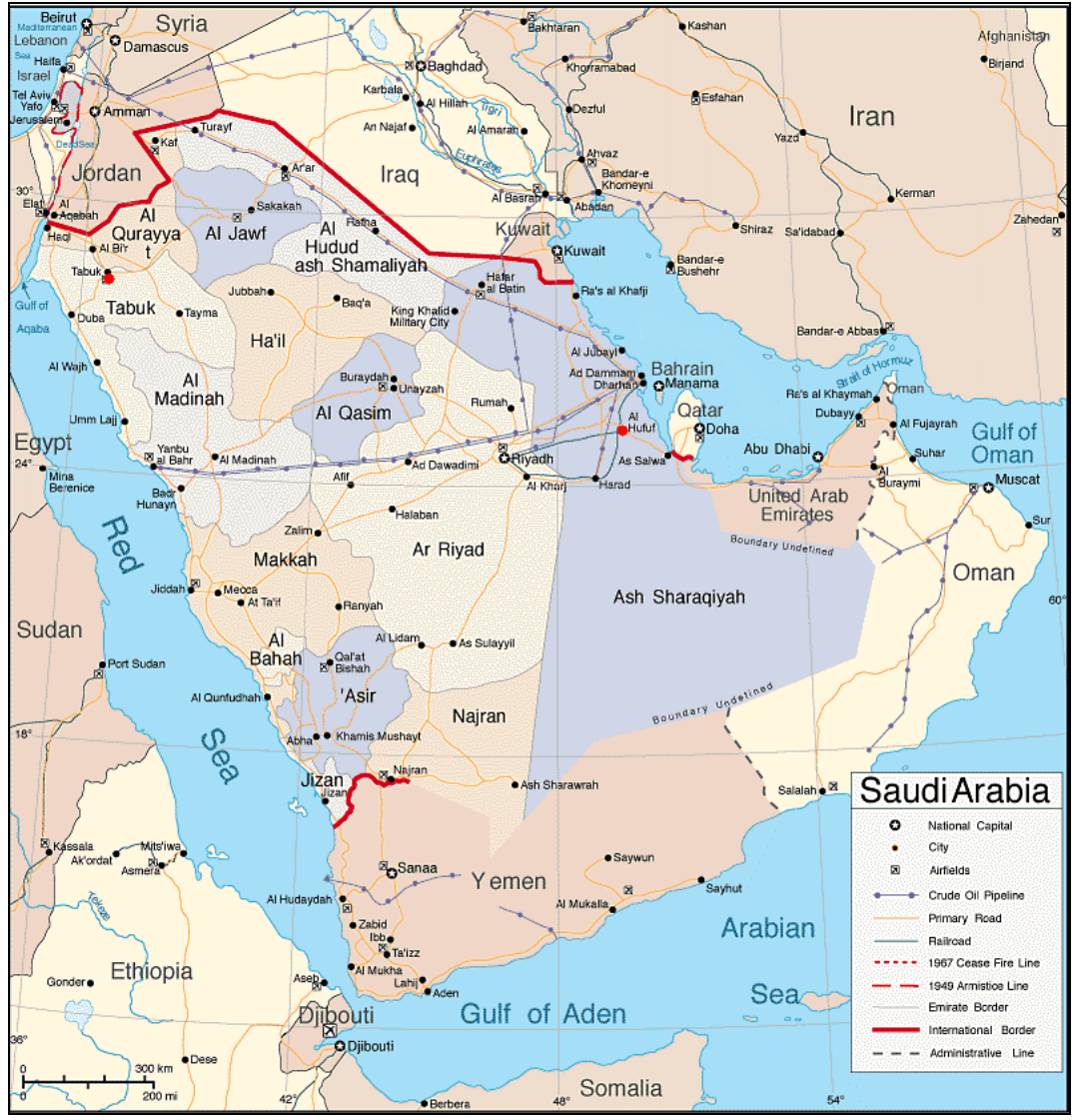

World Atlas [15].

Figure 1: $\quad$ Show Al-Hassa (Eastern part) and Tabouk (Northern west part) locations. 
The public attitude towards wastewater related to animals, crops and greenhouse vegetables was a negative vote $(80 \%)$. This negative attitude was due to the consumers' fear of toxic substances which can not be removed by existing water treatment technology. The public showed a strong reluctance towards wastewater to be applied in food production schemes (Kantanoleon et al. [13]) .

Public is seen as key reason for acceptance or rejection of wastewater reuse. It is commonly assumed that sustainable wastewater reuse projects failed because less public were educated and this leads to reject readily change. In other words, there is a lack of understanding about risk and the belief as they contain advanced information. The public voice should engage in sustainable schemes, so recognising that public engagement is required. Public should be familiarised about potential risk and the value of sustainability (Stenekes et al. [14]).

This paper provides an overview of the survey-based part of a study concerning wastewater reuse in the KSA. This study targeted a total of 400 eligible consumers to determine public attitudes towards wastewater reuse practices in two main agricultural cities within the KSA (Figure 1): Al-Hassa, where there is an existing large-scale wastewater reuse project for unrestrictedirrigation, and Tabouk, where there is very limited wastewater reuse; mainly irrigating beautification trees on a small scale.

The study aim is to identify public perceptions of wastewater reuse and how these might affect current and future use of the water resources.

\section{Methodology}

The survey was conducted between December 2009 and March 2010. A systematic-random sample of 400 adult residents was undertaken, with equal representation according to gender and area of residence (Al-Hassa and Tabouk). Respondents were screened for eligibility in terms of age (18 years and older) and for consumption of food products of interest.

The questionnaire was designed as a self-completion document and consisted of five thematic sections: attitudes to shopping, attitudes to wastewater reuse, attitudes towards agricultural food and safety, attitudes to agricultural food shopping behaviour and participants' demography.

In this paper particular emphasis is given to a scale of the acceptability of wastewater reuse. The construct of attitudes to acceptability of wastewater reuse was designed as a 12-item, 5-point agreement scale (Likert scale) linked to statements about acceptability of wastewater reuse practices $(1=$ strongly disagree, 5 = strongly agree) (Oppenheim [16]).

The initial version of the questionnaire was developed from the literature [12, 17-19]. It was subsequently refined from the results of focus group research with food consumers in each region (i.e. Al-Hassa and Tabouk), and further refined through consultation with colleagues experienced in consumer behaviour and scale development. The focus group discussions helped to clarify related issues, to generate hypotheses, to understand subconscious motivation for food purchase and, to reveal the perceptions, experience and knowledge of participants. Hence 
the focus group research contributed valuable insights that were used to improve the structure and content of the questionnaires.

A paper copy of the questionnaire was pre-tested using a sample of consumers. In response to feedback, minor modifications to question wording were made to represent the context of the survey. Following these modifications, the final version of the questionnaire was judged to possess face and context validity (De Vellis [20]) and that respondents would be able to complete the questionnaire comfortably. However, provision was made for a facilitator to be available during the completion of the questionnaire to assist the respondent.

Scale reliability for the scale of the acceptability of wastewater reuse was evaluated using Cronbach's alpha coefficient; a measure of how well a set of manifest indicators measure the scale [20]. The analysis indicates an alpha coefficient of 0.9 . There is no universal convention with respect to the minimum acceptable threshold value; Nunally [21] recommends an alpha value of 0.7 , while Robinson et al., in Hair et al. [22] suggest that a value of 0.6 is acceptable for exploratory research. Hence according to these criteria it is evident that the reliability of the scale can be judged as acceptable.

\subsection{Factor analysis}

Factor analysis is a multivariate technique that identifies the dimensions of the original observed measures of a scale in terms of a hierarchical structure of nonobserved latent variables or factors. The items in the original scale should be metric and correlated. The factors are derived in descending order of importance in terms of their contributions to the explanation of the total variance of the scale. The broad aims of the analysis are to identify the number of factors and interpret what they represent.

The theoretical framework is the factor model that explains the observation on the original variable, its variance and the covariance between pairs of variables. According to the model the original variables are determined by a linear combination of common factors and the influence of a unique factor. The model is based upon a series of assumptions. The original variables and the common factors are standardised to have zero mean and unit variance. The covariances between common factors, unique factors and between pairs of common factors and unique factors are zero.

\section{Results}

\subsection{Factor analysis}

Factor analysis was applied to the 12-item five-point scale concerned with attitudes to water reuse. The analysis employed principal components analysis and extracted factors with eigenvalues greater than unity with Varimax rotation. Confirmation that the test variables are inter-correlated is indicated by a KMO index of 0.811 , categorised by Kaiser [23] as "Meritorious", while Bartlett's Test of Sphericity results in the rejection of the null hypothesis at the five percent 
significance level $\left(\chi^{2}(66)=2340.932, \mathrm{p}<0.05\right)$. The analysis produced a solution in three factors (Table 2 ).

Table 2: $\quad$ Rotated factor analysis solution.

\begin{tabular}{lcccc}
\hline Measure & \multicolumn{3}{c}{ Factor Number } & h2 \\
& 1 & 2 & 3 & \\
\hline Water public park & .105 & .058 & .756 & .586 \\
Toilet flushing & -.134 & .185 & .692 & .531 \\
Water home garden & .427 & .104 & .720 & .712 \\
Water sport field & .203 & -.043 & .765 & .628 \\
Irrigate fodder crops & .773 & .079 & .224 & .654 \\
Irrigate cereal crops & .884 & .196 & .132 & .838 \\
Irrigate fruit crops & .705 & .342 & .029 & .615 \\
Irrigate vegetable crops & .812 & .346 & .081 & .785 \\
Washing clothes & .267 & .626 & .303 & .555 \\
Showering/bathing & .282 & .790 & .187 & .739 \\
Cooking & .359 & .766 & .018 & .716 \\
Drinking & .047 & .874 & -.061 & .769 \\
Eigenvalue & 4.871 & 1.923 & 1.333 & \\
Variance \% & 40.589 & 16.024 & 11.105 & \\
Cumulative \% & 40.589 & 56.613 & 67.718 & \\
\hline
\end{tabular}

Notes

h2 refers to communality

Extraction Method: Principal Component Analysis.

Rotation Method: Varimax with Kaiser Normalization.

\subsection{Goodness of fit}

Approximately 67 per cent of total variance is explained by the three factors. The communalities are generally respectable and approximate to values of at least 0.6 .

\subsection{Interpretation of factors}

The interpretation of factors is established through the strength of correlations between each factor and the original scale items. Factor 1 is correlated with the 
original items 'Irrigate cereal crops', 'Irrigate vegetable crops ', 'Irrigate fodder crops', and 'Irrigate fruit crops'. This factor is defined as the acceptability of agricultural use. Factor 2 is correlated with 'Drinking', 'Showering/bathing', 'Cooking', and 'Washing clothes'. This factor is defined as the acceptability of domestic use. Factor 3 is correlated with 'Water sport field', 'Water sport field', 'Water home garden' and, 'Toilet flushing'. This factor is defined as the acceptability of public use. Reliability analysis of the measures associated with the three factors are, respectively, $0.9,0.8$ and 0.7 so that each set of measures achieves the suggested minimum threshold of 0.7 (Nunally [21]).

\subsection{Testing for differences between communities}

Factor analysis establishes the dimensions underlying residents' attitudes to waste water reuse. Further examination of the differences between communities is provided by the use of factor scores, in this case three scores, generated for each respondent, in association with a comparison of means test under the null hypothesis that the acceptability of water reuse is equal between the consumers of Al-Hassa and Tabouk.

Results (Table 3) reveal that there are significant differences between consumers in terms of agricultural use $(\operatorname{sig}=.001)$ and public use ( $\operatorname{sig}=.031)$, but not for domestic use $(\operatorname{sig}=.140)$. Furthermore it is evident that residents of Al Hassa have more positive attitudes to wastewater reuse than those in Tabouk.

Table 3: Comparison of factor score means between communities.

\begin{tabular}{|c|c|c|c|c|}
\hline \multirow[b]{2}{*}{ Acceptability Factor 1} & \multicolumn{2}{|c|}{ Average for community } & \multirow[b]{2}{*}{$\begin{array}{c}\text { Overall } \\
\text { Mean }\end{array}$} & \multirow[b]{2}{*}{ Sig Stat2 } \\
\hline & Al Hassa & Tabouk & & \\
\hline Agricultural use & 0.436 & -0.493 & 0.000 & 0.000 \\
\hline Domestic use & 0.071 & -0.081 & 0.000 & 0.140 \\
\hline Public use & 0.104 & -0.118 & 0.000 & 0.031 \\
\hline
\end{tabular}

Notes:

Designed as a 5-point importance rating where $1=$ strongly disagree and $5=$ strongly agree.

Sig Stat defines the significance statistic in association with a test for the equality of group means at the 5 per cent significance level.

\section{Discussion}

The results reveal that for each dimension of wastewater reuse, Al-Hassa residents are more positive than Tabouk residents. The rationale for the results is most likely to be related to the familiarity of Al-Hassa consumers because of the existence of a waste water project in that area. This could be used to advantage in a social policy marketing context with the use of testimonials and discussions of positive experiences using social media. 
It is also evident that the implied ranking of acceptability differs between the two communities. Al-Hassa residents rank each use in descending order as agricultural use, public use, and domestic use. In contrast, Tabouk residents reveal a ranking of domestic use, public use and agricultural use.

Policy makers should emphasise that public engagement in sustainable wastewater projects is important. By doing so, it would be a requirement to familiarise the public with wastewater uses potential risk and what is the value of sustainability.

\section{Conclusion}

The study indicates that it is possible to explore residents' attitudes to the acceptability of wastewater reuse in terms of a scale with 12 measures, and that the measures possess acceptable reliability. Factor analysis of this scale reveals that there are three dimensions, interpreted in descending order of importance, as the acceptability of agricultural use, domestic use and, public use. Statistical analysis of the differences in attitudes between residents in the two communities that constituted the sample, indicate that residents in Al-Hassa are more supportive of wastewater reuse than those in Tabouk. We interpret this preliminary analysis as providing an encouraging indication that familiarity with wastewater reuse reduces the level of concern. In other words, the perceived risk associated with wastewater reuse declines with experience. Additional analysis is in progress to capture the opinions of water users (farmers) at the same sites.

\section{References}

[1] Water for Food, Water for Life: A Comprehensive Assessment of Water Management in Agriculture. Earthscan, and Colombo: International Water Management Institute: London, 2007.

[2] Hinrichsen, D., Robey, B., A, M. and Upadhyay, U. Solutions for a WaterShort World. Maryland: Population Information Program, Centre for Communication Programs, the Johns Hopkins School of Public Health, 1998.

[3] Abderrahman, W. A. 'Groundwater management for sustainable development of urban and rural areas in extremely arid regions: A case study', International Journal of Water Resources Development, 21, (3), pp. 403-412, 2005.

[4] Al-Ibrahim, A. A. 'Water Use in Saudi Arabia: Problems and Policy Implications', Journal of Water Resources Planning and Management, 116, (3), pp. 375-388, 1990.

[5] FAO. Agricultural Drainage Water Management in Arid and Semi-arid Areas. Rome, 2002.

[6] Scott, C. A., Faruqui N.I. and Raschid-Sally, L. (eds.) Wastewater Use in Irrigated Agriculture: Coordinating the Livelihood and Environmental Realities. CABI, Wallingford, 2004. 
[7] Wegner-Gwidt, J. Winning support for reclamation projects through proactive communication programs. Water Science and Technology 24 (9), 313-322, 1991.

[8] Jeffrey, P., Temple, C., Sustainable water management: some technological and social dimensions of water recycling. Sustainable Development International 1, 63-66, 1999

[9] Torres, A. 'Public acceptance is not optional', Water Environment and Technology, 15, (12), pp. 60-61, 2003.

[10] Po, M., Nancarrow, B., Leviston, Z., Porter, N., Syme, G. and Kaercher, J. Predicting Community Behaviour in Relation to Wastewater Reuse: What Drives Decisions to Accept or Reject? : Commonwealth Scientific and Industrial Research Organisation, Australia, 2005.

[11] Ahmad, S. 'Public Attitude towards Water and Water Reuse', Water Science and Technology, 23, (10-12), pp. 2165-2170, 1991.

[12] Friedler, E., Lahav, O., Jizhaki, H. and Lahav, T. 'Study of urban population attitudes towards various wastewater reuse options: Israel as a case study', Journal of Environmental Management, 81, (4), pp. 360-370, 2006.

[13] Kantanoleon, N., Zampetakis, L. and Manios, T. 'Public perspective towards wastewater reuse in a medium size, seaside, Mediterranean city: A pilot survey', Resources, Conservation and Recycling, 50, (3), pp. 282-292, 2007.

[14] Stenekes, N., Colebatch, H. K., Waite, T. D. and Ashbolt, N. J. 'Risk and Governance in Water Recycling: Public Acceptance Revisited', Science Technology Human Values, 31, (2), pp. 107-134, 2006.

[15] World Atlas (undated ) Saudi Arabia Maps and Information Available at: http://www.worldatlas.com/webimage/countrys/asia/sa.htm

[16] Oppenheim, A. N. Questionnaire Design, Interviewing and Attitude Measurement. Pinter Publishers Ltd: London, 1992.

[17] Dolnicar, S. and Schäfer, A. I. 'Desalinated versus recycled water: Public perceptions and profiles of the accepters', Journal of Environmental Management, 90, (2), pp. 888-900, 2009.

[18] Jeffrey, P. 'Public Attitudes to In-House Water Recycling in England and Wales', Water and Environment Journal, 16, (3), pp. 214-217, 2002.

[19] Faruqui, N., I., Biswas, A., K., and Bino, M., J. (eds.) WATER MANAGEMENT IN ISLAM. The United Nations University Press: Tokyo:, 2001.

[20] De Vellis, R. F. Scale Development (2nd edition), Sage Publications Inc.: London, pp 47-59, 2003.

[21] Nunally, J.C. Psychometric Theory. McGraw-Hill: New York, 1978.

[22] Hair J.F., Black W.C., Babin, B. J., and Anderson R.E. Multivariate data analysis; a global perspective ( $7^{\text {th }}$ Edition). Upper Saddle River, New Jersey: Pearson Education, Inc, pp 125, 2010.

[23] Kaiser, H. F. An index of factorial simplicity. Psychometrika, 39, 31-36, 1974. 